\title{
Intraoperative radiotherapy boost as part of breast-conservation therapy for breast cancer: a single-institution retrospective analysis
}

\author{
Raluca Stoian ${ }^{1,2}$ - Thalia Erbes ${ }^{3,4}$ - Constantinos Zamboglou1,2 • Jutta Scholber1,2 • Mark Gainey ${ }^{1,2}$. \\ Ilias Sachpazidis ${ }^{1,2} \cdot$ Erik Haehl $^{1,2}$. Simon K. B. Spohn ${ }^{1,2}$ - Vivek Verma ${ }^{5}$ David Krug $^{6} \cdot$ Alexander Rühle $^{1,2,7}$. \\ Ingolf Juhasz-Böss ${ }^{3}$ - Anca-Ligia Grosu'1,2 • Nils H. Nicolay ${ }^{1,2,7}$ - Tanja Sprave ${ }^{1,2}$
}

Received: 10 January 2021 / Accepted: 7 April 2021 / Published online: 30 April 2021

(c) The Author(s) 2021

\begin{abstract}
Background There are currently no data from randomized controlled trials on the use of intraoperative radiotherapy (IORT) as a tumor bed boost as part of a breast-conservation approach for breast cancer. This study retrospectively reviewed the safety and efficacy of IORT as a boost treatment at a tertiary cancer center.

Methods From 2015 to 2019, patients underwent breast-conserving surgery with axillary lymph node staging and a single dose of $20 \mathrm{~Gy}$ IORT with $50-\mathrm{kV}$ photons, followed by whole-breast irradiation (WBI) and adjuvant systemic therapy (if applicable). Patients were followed for assessment of acute and late toxicities (using the Common Terminology Criteria for Adverse Events version 5.0) at 3-6-month intervals. Outcomes included ipsilateral (IBTR) and contralateral breast progression-free survival (CBE), distant metastasis-free survival (DMFS), and overall survival (OS).
\end{abstract}

Availability of data and materials The data used in this analysis are available with the authors' permission.

\author{
Raluca Stoian \\ raluca.stoian@uniklinik-freiburg.de \\ Thalia Erbes \\ thalia.erbes@uniklinik-freiburg.de \\ Constantinos Zamboglou \\ constantinos.zamboglou@uniklinik-freiburg.de \\ Jutta Scholber \\ jutta.scholber@uniklinik-freiburg.de \\ Mark Gainey \\ mark.gainey@uniklinik-freiburg.de \\ Ilias Sachpazidis \\ ilias.sachpazidis@uniklinik-freiburg.de \\ Erik Haehl \\ erik.haehl@uniklinik-freiburg.de \\ Simon K. B. Spohn \\ simon.spohn@uniklinik-freiburg.de \\ Vivek Verma \\ vivek333@gmail.com \\ David Krug \\ david.krug@uksh.de \\ Alexander Rühle \\ alexander.ruehle@uniklinik-freiburg.de
}

Anca-Ligia Grosu

anca.grosu@uniklinik-freiburg.de

Nils H. Nicolay

nils.nicolay@dkfz.de

$\triangle$ Tanja Sprave, MD, MBA

tanja.sprave@uniklinik-freiburg.de

1 Department of Radiation Oncology, University Hospital of Freiburg, Robert-Koch-Straße 3, 79106 Freiburg, Germany

2 German Cancer Consortium (DKTK) Partner Site Freiburg, German Cancer Research Center (dkfz), Neuenheimer Feld 280, 69120 Heidelberg, Germany

3 Department of Obstetrics and Gynecology, Medical Center, University of Freiburg, Freiburg, Germany

4 Faculty of Medicine, University of Freiburg, Freiburg, Germany

5 Department of Radiation Oncology, Allegheny General Hospital, Pittsburgh, PA, USA

6 Department of Radiation Oncology, University Hospital Schleswig-Holstein, Arnold-Heller-Str. 3, 24105 Kiel, Germany

7 Department of Molecular and Radiation Oncology, German Cancer Research Center (dkfz), Neuenheimer Feld 280, 69120 Heidelberg, Germany 
Results Median follow-up for the 214 patients was 28 (range 2-59) months. Most patients had T1 disease ( $n=124$ ) and were clinically node negative. Only few patients had high-grade and/or triple-negative disease. The vast majority of patients underwent sentinel node biopsy, and $32(15 \%)$ required re-resection for initially positive margins. Finally, all tumor bed margins were clear. Nine $(4.2 \%)$ and $48(22.4 \%)$ patients underwent neoadjuvant and adjuvant chemotherapy, respectively. WBI was predominantly performed as conventionally fractionated WBI $(n=187,87.4 \%)$, and the median time from BCS to WBI was 54.5 days. IORT was delivered with a single dose of $20 \mathrm{~Gy}$. The median WBI dose was $50 \mathrm{~Gy}$ (range 29.4-50.4Gy). No patients experienced grade 4 events; acute grade 3 toxicities were limited to 17 (8\%) cases of radiation dermatitis. Postoperative toxicities were mild. After WBI only one case of late grade $\geq 2$ events was reported. There were two recurrences in the tumor bed and one contralateral breast event.

Conclusion This investigation provides additional preliminary data supporting the using of IORT in the boost setting and corroborates the existing literature. These encouraging results should be prospectively validated by the eventual publication of randomized studies such as TARGIT-B.

Keywords Early breast cancer · Breast-conservation therapy $\cdot$ Adjuvant radiation therapy $\cdot$ Boost $\cdot$ Intraoperative radiotherapy

$\begin{array}{ll}\text { Abbreviations } \\ \text { ALND } & \text { Axillary lymph node dissection } \\ \text { BCS } & \text { Breast-conservating surgery } \\ \text { CBE } & \text { Contralateral breast progression-free survival } \\ \text { CI } & \text { Confidence interval } \\ \text { DIBH } & \text { Deep-inspiration breath-hold } \\ \text { DMFS } & \text { Distant metastasis-free survival } \\ \text { ER } & \text { Estrogen receptor } \\ \text { HER2 } & \text { Human epidermal growth factor receptor } 2 \\ \text { HT } & \text { Hormonal therapy } \\ \text { IBTR } & \text { Ipsilateral breast progression-free survival } \\ \text { IORT } & \text { Intraoperative radiotherapy } \\ \text { IOERT } & \text { Intraoperative radiotherapy using electrons } \\ \text { OS } & \text { Overall survival } \\ \text { RT } & \text { Radiotherapy } \\ \text { SIB } & \text { Simultaneous integrated boost } \\ \text { SLND } & \text { Sentinel lymph node dissection } \\ \text { TNBC } & \text { Triple-negative breast cancer } \\ \text { VMAT } & \text { Volumetric modulated arc therapy } \\ \text { WBI } & \text { Whole-breast irradiation }\end{array}$

\section{Introduction}

Following breast-conserving surgery (BCS), radiotherapy (RT) reduces local recurrence and breast cancer mortality [1]. There is an additional reduction in local recurrence with the delivery of a focal RT boost to the tumor bed following whole-breast irradiation (WBI) [2]. External-beam RT is the most commonly used technique for adjuvant treatment of breast cancer; however, other modalities have been increasingly explored.

Intraoperative RT (IORT) is one such modality that has been used as a substitute for both WBI as well as in the boost setting [3, 4]. Randomized data for the former setting include the TARGIT-A and ELIOT trials [5, 6], and the accruing TARGIT-B (NCT01792726) and recently published HIOB (NCT01343459) [7] trials. IORT is delivered by means of electrons or $50-\mathrm{kV}$ X-ray therapy as a single fraction during the course of BCS.

IORT has been primarily analyzed for patients with lowrisk features. The sole use of IORT as a substitute for WBI was critically questioned. The current data demonstrate a tendency for higher local recurrence rates; therefore, the authors recommend critical patient selection for the use of IORT alone when omitting WBI [8].

IORT has several theoretical advantages, in particular "same-day approach" settings in addition to increased patient convenience [9]. IORT allows for increased skin sparing and avoids potential tumor repopulation between the completion of surgery and initiation of WBI. It also allows for a more accurate assessment of the dimensions of the operative tumor bed and, hence, potentially reduces irradiated volumes. In comparison to the scar boost using electrons, the risk of a potential target miss due to problems with identification of the tumor bed can be avoided. Notably, current guidelines allow a safe and reproducible boost definition even after the oncoplastic surgical procedures [10].

In the absence of published data from randomized trials of IORT as a boost, reporting institutional experiences is necessary. The goal of this single-institutional retrospective study was to describe outcomes and toxicities of IORT boost using 50-kV X-rays for early breast cancer.

\section{Materials and methods}

\section{Patients and treatment}

From 2015 to 2019, breast cancer patients treated with a single dose of $20 \mathrm{~Gy}$ IORT as a tumor bed boost were included in this analysis. Institutional criteria for patient 


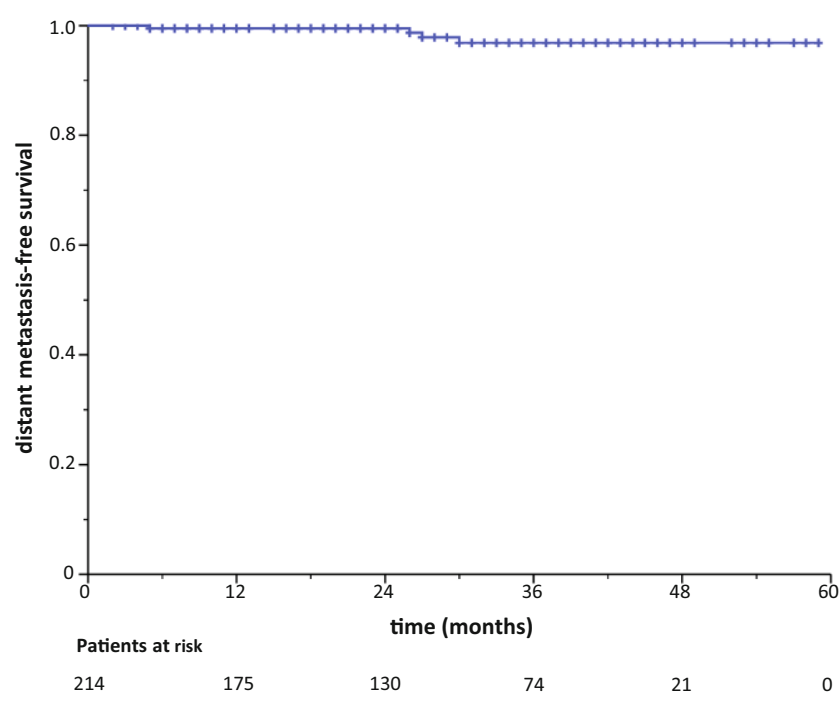

Fig. 1 Kaplan-Meier curve for distant metastasis-free survival

selection for IORT boost included patients with BCS, premenopausal status, postmenopausal in addition to the following risk factors: tumor size $\geq 2 \mathrm{~cm}$, extensive intraductal component, G3, HER2-positive, and triple-negative breast cancer (TNBC).

BCS with sentinel lymph node excision or axillary nodal dissection was performed according to institutional protocols. Neoadjuvant or adjuvant chemotherapy as well as endocrine therapy was administered based on the currently valid guidelines and individual recommendations of the interdisciplinary oncological board.

IORT was performed with the following methodology: following wide tumor excision, a single IORT dose was prescribed to the applicator surface (range 20-50 mm) and skin-sparingly applied using $50-\mathrm{kV} \mathrm{X}$-rays with the INTRABEAM miniature X-ray generator (Carl Zeiss Surgical, Oberkochen, Germany) (Fig. 1). IORT boost with a single dose of $20 \mathrm{~Gy}$ at the surface of the IORT applicator using $50-\mathrm{kV}$ photons is attenuated down to $5 \mathrm{~Gy}$ at $1 \mathrm{~cm}$ distance from the edge of the excision cavity.

Special care was taken to minimize skin exposure during IORT. Subsequently, after completion of wound healing, WBI was delivered according to standardized institutional protocols, using conventional fractionation $(50-50.4 \mathrm{~Gy}$ in $25-28$ fractions) or hypofractionation $(40.05 \mathrm{~Gy}$ in 15 fractions). Depending on the time period-beginning in 2017 was increasingly used for adjuvant WBI). CT-based (Brilliance, CT Big Bore, Philips, Cleveland, OH) three-dimensional treatment planning (Oncentra MasterPlan, Nucletron, Veenendaal, the Netherlands and/or Eclipse ${ }^{\mathrm{TM}}$ planning systems, Varian Medical Systems) was performed using standard tangential treatment portals (6 or 18 MV; Synergy; Elekta, Crawley, United Kingdom). From 2017, patients with left-sided breast cancer received WBI in deep-inspi- rational breath-hold (DIBH) technique with Surface Image Guided RT (C-RAD, Catalyst, C-RAD AB, Uppsala, Sweden). In some cases with anatomical variations, an intensitymodulated RT (IMRT) or volumetric modulated arc therapy (VMAT) technique was used to reduce the lung and heart dose.

Systemic therapy was administered according to national and international guidelines (the Gynecologic Oncology Working Group recommendations, S3 guideline, St. Gallen consensus). Following WBI, patients with estrogen receptor (ER)-positive disease received 5-10 years of adjuvant endocrine therapy. Breast ultrasound was performed every 6 months for the first 3 years. Mammograms were obtained 6 months after WBI, and yearly after the first mammography. Suspected recurrences were biopsy confirmed.

All patients were followed-up every 3-6 months for the first 2 years in the radiation oncology department, followed by annual visits thereafter. Acute toxicity assessments were conducted at each visit according to the Common Terminology Criteria for Adverse Events (CTCAE) version 5.0. Late toxicity was assessed by the treating radiation oncologists and gynecologist based on modified Late Effects in Normal Tissues criteria (Subjective, Objective, Management, and Analytic, LENT-SOMA). For this purpose, the planning CT scans and ultrasound examinations were evaluated. According to this, seroma and hematoma were classified as grade 1 (asymptomatic), 2 (simple aspiration needed), and 3 (surgical intervention).

\section{Statistical analysis}

Outcomes included ipsilateral breast progression-free survival (IBTR), contralateral breast progression-free survival (CBE), distant metastasis-free survival (DMFS), and overall survival (OS). All were defined from the date of IORT to the pertinent event. Survival times were calculated using the Kaplan-Meier method. Data are reported as a mean, median (range), and frequencies. Binary correlation analysis using Spearman rank correlation to examine the impact of various determinants (in particular applicator size, systemic therapy, or fractionation regimen) on acute and late toxicity was used. $P$-values $<0.05$ were considered statistically significant. Statistics were performed with SPSS version 25 (IBM, Armonk, NY, USA).

\section{Results}

Altogether, 214 patients were analyzed for this investigation. Table 1 displays clinical characteristics of this population. Most patients had T1 disease $(n=124)$ and were clinically node negative. Only few patients had high-grade and/or triple-negative disease. 
Table 1 Patient and tumor characteristics

\begin{tabular}{|c|c|}
\hline \multicolumn{2}{|l|}{ Treatment characteristics } \\
\hline Total $n=214$ patients & $n(\%)$ \\
\hline $\mathrm{BCS}$ & $214(100)$ \\
\hline SLND & $208(97.2)$ \\
\hline ALND & $7(3.3)$ \\
\hline \multicolumn{2}{|l|}{ Resection status } \\
\hline R0 & $185(86.4)$ \\
\hline $\mathrm{R} 1$ & $23(10.7)$ \\
\hline Re-resection needed due to $\mathrm{R}+$ status & $32(15.0)$ \\
\hline Neoadjuvant chemotherapy & $9(4.2)$ \\
\hline Adjuvant chemotherapy & $48(22.4)$ \\
\hline Endocrine therapy & $208(97.2)$ \\
\hline Simultaneous & $9(4.3)$ \\
\hline Adjuvant & $53(25.5)$ \\
\hline Upfront & $146(70.2)$ \\
\hline \multicolumn{2}{|l|}{ IORT dose } \\
\hline 20 Gy & $214(100)$ \\
\hline Applicator surface median (mm) & $35(20-50)$ \\
\hline \multicolumn{2}{|l|}{ WBI } \\
\hline Normofractionated $(25-28 \times)$ & $187(87.4)$ \\
\hline Hypofractionated $(15 \times)$ & $25(11.7)$ \\
\hline Not applied & $2(0.9)$ \\
\hline 3DRT & $200(94.3)$ \\
\hline IMRT/VMAT & $12(5.7)$ \\
\hline DIBH & $33(15.6)$ \\
\hline Median time (days) from IORT to WBI (range) & $54.5(21-325)$ \\
\hline \multicolumn{2}{|l|}{ Regional nodal irradiation } \\
\hline Normo-fractionated $(28 \times)$ & $11(5.1)$ \\
\hline
\end{tabular}

Patient and tumor characteristics of patients treated by IORT and WBI in our institution between 2009 and $2019(n=214)$. Staging of breast cancer was based on the 7th Edition of the UICC TNM classification $A L N D$ axillary lymph node dissection, $B C S$ breast-conserving surgery, $D I B H$ deep-inspiration breath-hold technique, 3DRT 3D-conformal radiotherapy, Gy gray, IMRT intensity modulated radiotherapy, IORT intraoperative radiotherapy, $L N$ lymph node, $M E$ mastectomy, $S L N D$ sentinel lymph node dissection, VMAT volumetric modulated arc therapy, $W B I$ whole breast irradiation

Table 2 shows treatment-related parameters. The vast majority of patients underwent sentinel node biopsy and $32(15 \%)$ required re-resection for initially positive margins. Re-resection for $\mathrm{R}+$ was performed as part of the first surgery in 13 patients. The remaining 19 patients underwent a second procedure with re-resection. IORT was performed as part of the first surgery in each case.

After re-resection, all tumor bed margins were clear. Nine $(4.2 \%)$ and $48(22.4 \%)$ patients underwent neoadjuvant and adjuvant chemotherapy, respectively. The vast majority $(n=187,87.4 \%)$ received conventionally fractionated WBI, and the median time from BCS to WBI was 54.5 (range 21-325) days. IORT was successfully delivered in all cases, to a median dose of $20 \mathrm{~Gy}$ using applicator surface median $35 \mathrm{~mm}$ (range $20-50 \mathrm{~mm}$ ). WBI was applied using
Table 2 Treatment characteristics

\begin{tabular}{ll}
\hline Treatment characteristics & $\boldsymbol{n}(\boldsymbol{\%})$ \\
\hline Total $\boldsymbol{n}=\mathbf{2 1 4}$ patients & $214(100)$ \\
BCS & $208(97.2)$ \\
SLND & $7(3.3)$ \\
ALND & \\
Resection status & $185(86.4)$ \\
R0 & $23(10.7)$ \\
R1 & $32(15.0)$ \\
Re-resection needed due to R+ status & $9(4.2)$ \\
Neoadjuvant chemotherapy & $48(22.4)$ \\
Adjuvant chemotherapy & $208(97.2)$ \\
Endocrine therapy & $9(4.3)$ \\
Simultaneous & $53(25.5)$ \\
Adjuvant & $146(70.2)$ \\
Upfront & \\
IORT dose & $214(100)$ \\
20Gy & $35(20-50)$ \\
Applicator surface median (mm) & \\
WBI & $187(87.4)$ \\
Normofractionated $(25-28 \times)$ & $25(11.7)$ \\
Hypofractionated $(15 \times)$ & $2(0.9)$ \\
Not applied & $200(94.3)$ \\
3DRT & $12(5.7)$ \\
IMRT/VMAT & $33(15.6)$ \\
DIBH & $54.5(21-325)$ \\
Median time (days) from IORT to WBI (range) & \\
\hline & \\
\hline
\end{tabular}

Treatment details for radiotherapy using IORT and WBI of breast cancer patients $(n=214)$.

$A L N D$ axillary lymph node dissection, $B C S$ breast-conserving surgery, $D I B H$ deep-inspiration breath-hold technique, 3DRT 3D-conformal radiotherapy, Gy gray, IMRT intensity modulated radiotherapy, IORT intraoperative radiotherapy, $L N$ lymph node, $M E$ mastectomy, $S L N D$ sentinel lymph node dissection, VMAT volumetric modulated arc therapy, $W B I$ whole breast irradiation

standard tangential treatment portals in most cases (94.2\%). Only 12 patients $(5.7 \%)$ received WBI using IMRT/VMAT. The median WBI dose was 50 Gy (range 29.4-50.4Gy); 2 $(0.9 \%)$ did not receive WBI. These patients renounced WBI explicitly due to own request or advanced age, while guaranteeing a close clinical follow-up and adjuvant systemic therapy. All patients with pN2a $(n=3)$ and 8 patients with pN1a (since 2017) received normofractionated RT to the regional lymph node levels with $50.4 \mathrm{~Gy}$ in 28 fractions.

Table 3 demonstrates the toxicity profile of the study population. No patients experienced grade 4 events, and grade 3 toxicities after WBI were limited to $17(8 \%)$ cases of radiation dermatitis. Postoperative toxicities occurring before WBI were mild, no case of grade 2 seroma/ 
Table 3 Toxicity

\begin{tabular}{|c|c|c|c|c|}
\hline \multirow[b]{2}{*}{ Total $=214$ patients } & \multicolumn{4}{|c|}{ Toxicity grade $n(\%)$} \\
\hline & 0 & 1 & 2 & 3 \\
\hline \multicolumn{5}{|l|}{ Toxicity: post IORT } \\
\hline Dermatitis & $211(98.6)$ & $3(1.4)$ & - & - \\
\hline Seroma/hematoma breast & $192(89.7)$ & $22(10.3)$ & - & - \\
\hline Seroma/hematoma axilla & $212(99.1)$ & $2(0.9)$ & - & - \\
\hline Wound infection & $210(98.1)$ & $4(1.9)$ & - & - \\
\hline Wound dehiscence & $210(98.1)$ & $4(1.9)$ & - & - \\
\hline Total $=212$ patients & - & - & - & - \\
\hline \multicolumn{5}{|l|}{ Acute toxicity post WBI } \\
\hline Dermatitis & $13(6.1)$ & $100(46.7)$ & $82(38.7)$ & $17(8.0)$ \\
\hline Seroma/hematoma breast & $182(85.8)$ & $29(13.7)$ & $1(0.5)$ & - \\
\hline Seroma/hematoma axilla & $211(99.5)$ & $1(0.5)$ & - & - \\
\hline Wound infection & $208(98.1)$ & $1(1.9)$ & - & - \\
\hline Wound dehiscence & $209(98.6)$ & $3(1.9)$ & - & - \\
\hline Fatigue & $161(75.9)$ & $50(23.6)$ & $1(0.5)$ & - \\
\hline Pain & $168(79.2)$ & $44(20.8)$ & - & - \\
\hline Lymphodema & $192(90.6)$ & $20(9.4)$ & - & - \\
\hline \multicolumn{5}{|l|}{ Late toxicity post WBI } \\
\hline Dermatitis & $201(94.8)$ & $11(5.2)$ & - & - \\
\hline Seroma/hematoma breast & $188(88.7)$ & $24(11.3)$ & - & - \\
\hline Seroma/hematoma axilla & $211(99.5)$ & $1(0.5)$ & - & - \\
\hline Wound infection & $211(99.5)$ & $1(0.5)$ & - & - \\
\hline Fatigue & $187(88.2)$ & $24(11.3)$ & $1(0.5)$ & - \\
\hline Pain & $185(87.3)$ & $27(12.7)$ & - & - \\
\hline Lymphoedema & $184(86.8)$ & $28(13.2)$ & - & - \\
\hline
\end{tabular}

Acute and chronic radiotherapy-related toxicities after IORT and WBI according to the Common Terminology Criteria for Adverse Events (CTCAE v5.0)

IORT intraoperative radiotherapy, WBI whole breast irradiation

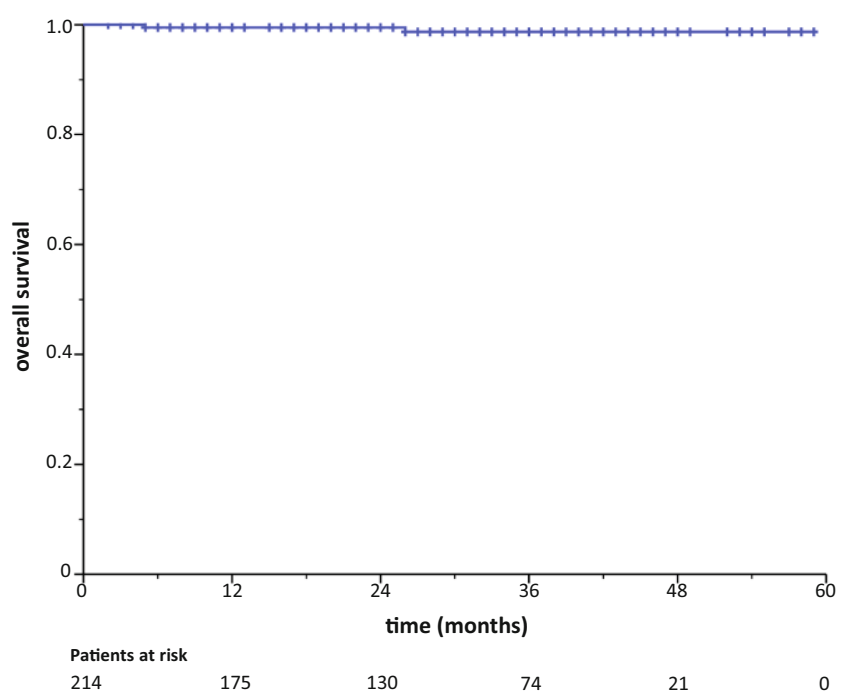

Fig. 2 Kaplan-Meier curve for overall survival hematoma occurred. Late toxicities were also mild, with just one case of a late grade $\geq 2$ event.

With 28 months (range 2-59 months) median followup, two recurrences in the tumor bed and one contralateral breast event have occurred. The 3-year ipsilateral breast recurrence rate (IBRT) and contralateral breast recurrence (CBE) rate were $1.8 \%$ (95\% CI 99.5-92.7\%) and $0.6 \%$ (95\% CI 99.9-95.9\%), respectively. The 3-year DMFS and OS rates were $96.8 \%$ (95\% CI $98.8-91.6 \%$ ) and $98.7 \%$ (95\% CI 99.7-94.7\%), respectively (Figs. 1 and 2).

Lastly, binary correlation analysis did not reveal statistically significant associations between any particular variables (in particular applicator size, systemic therapy, neoadjuvant chemotherapy) and the risk of acute and chronic toxicity. Only hypofractionated WBI (Spearman rank correlation $r_{s}=-0.197, p=0.004$, Cohen's effect size: weak to moderate) was significantly correlated with increased occurrence of acute dermatitis. 


\section{Discussion}

This single-institutional retrospective investigation demonstrates preliminary results on IORT boost with $50-\mathrm{kV}$ photons regarding the feasibility, mild toxicities, and association with appropriate early oncological outcomes for breast cancer.

There are few reports on the use of IORT as a tumor bed boost. Wenz et al. reported a clear correlation between breast volume, applicator size, and degree of fibrosis with comparable techniques [11]. The long-term analysis from the same institution after 78 months in 400 patients demonstrated on the one hand low in-breast and axillary node recurrence rates and on the other hand, few high-grade adverse events, mostly fibrosis and pain. The majority of late side effects occurred during the first 3 years after IORT and WBI [12]. In light of this, given the short follow-up time in our collective with median 28 months, chronic toxicity may be underrepresented. Furthermore Wenz et al. reported the development of higher-grade fibrosis grade II-III after a median of 36 months as an effect of a possibly shorter interval ( $<30$ days) between IORT and WBI [13]. These findings and recommendations to keep an interval between IORT and WBI of about 5-6 weeks were integrated into our clinical routine early on. In our cohort only $4.2 \%(n=9)$ of patients had an interval of $<30$ days and $12.7 \%(n=27)$ of patients had a cumulative interval of $<35$ days with a median interval of 54 days between IORT and WBI.

The largest experience is available for the IORT using electrons (IOERT) prescribed such a boost [14]. IOERT also offers satisfactory oncological outcomes in groups with a high risk for local relapse, like TNBC [15]. In a retrospective analysis comparing IOERT as an anticipated boost to patients treated with conventional percutaneous boost, improved local and locoregional control could also be shown in locally advanced stages (initial clinical stages II and III) after neoadjuvant chemotherapy [16].

When considering local antitumor efficacy, it is important to consider that the IORT boost with a single dose of $20 \mathrm{~Gy}$ at the surface of the IORT applicator using 50$\mathrm{kV}$ photons is attenuated to $5 \mathrm{~Gy}$ at $1 \mathrm{~cm}$ from the edge of the excision cavity. Analyses of wound fluid from patients treated with IORT suggest that IORT has a positive effect on the tumor microenvironment. Noteworthily, a high single IORT dose elicits impact beyond the direct killing of residual tumor cells, because of influencing the microenvironment in the wound fluid through the interruption of the proliferative cytokine cascade and downregulation of the local expression of epidermal growth factor [17, 18]. Taking into account the limited spatial range and significant dose attenuation to $5 \mathrm{~Gy}$ at $1 \mathrm{~cm}$ depth from the edge of the excision cavity, it is questionable what effect level and efficacy would be expected.
The comprehensive adoption of a reconstructive approach during breast-conserving surgery is mostly termed oncoplastic surgery. This concept has been introduced to allow wide excision for BCS and simultaneously minimize cosmetic impairment [19]. Notwithstanding clip marking of the tumor bed, postoperative delineation of the tumor bed after oncoplastic surgery can be challenging and represents a risk for geographic miss [20,21]. $\mathrm{IO}(\mathrm{E}) \mathrm{RT}$ is commonly performed prior to the reconstruction and/or remodeling procedure and enables precise and accurate dose delivery to the tumor bed.

On the basis of a low $\alpha / \beta$ ratio for breast cancer in the range of 3.5 to 4 [22-24], hypofractionation has been studied by a number of prospective phase III trials [25-31]. In our analysis, only $11.7 \%(n=25)$ of patients received hypofractionated WBI. The use of IOERT boost (11.1 Gy) and hypofractionated WBI (40.5 Gy in 15 fractions) was studied within the non-randomized HIOB study [7]. The HIOB trial demonstrated an excellent acute and late toxicity profile without cosmetic impairment after 3 years of follow-up [7]. Grade II-III fibrosis in the tumor bed occurred in 6\% (range 3-8.9) of patients [7]. In comparison, in our cohort, hypofractionated WBI was significantly correlated only with acute dermatitis. Another non-randomized phase II study evaluated hypofractionated WBI of $36.63 \mathrm{~Gy}$ in 11 fractions, followed by a sequential percutaneous boost of $13.32 \mathrm{~Gy}$ in 4 fractions [32]. The estimated 5-year locoregional and distant control rates were $98 \%$ in each case. Secondary endpoints were acute and late toxicity, which were assessed with grade II-III in $30 \% / 10 \%$ and $1 \% / 3 \%$, respectively [32]. Another approach to shorten overall treatment time is to use a simultaneous integrated boost (SIB). Data from three randomized controlled trials comparing normofractionated WBI with a SIB to normofractionated WBI with sequential boost have been published recently [33-35]. Oncological outcomes were comparable, and two of the three trials showed reduced acute toxicity with the SIB approach [33, 35].

Our findings are similar to those of existing data using IORT as a boost, demonstrating a 5-year IBTR rate of $\leq 5 \%$, along with a similar rate of acute grade $\geq 3$ and late grade $\geq 2$ toxicities [36-43]. The rate of postoperative complications was also low in this study and numerically comparable to existing data, corroborating that IORT is safe from this standpoint as well. Our data compare favorably in terms of chronic toxicity with no case of fibrosis grade $\geq$ II (Table 3).

Despite these encouraging results, limitations of this investigation should be acknowledged. This first relates to the single-institutional and retrospective nature of this study, including careful patient selection for IORT, thus limiting applicability to other patient populations. Additionally, newer data have now provided more detailed information about 
the limited benefit/risk ratio for applying boost treatments to low-risk patients. Additionally, the short follow-up of this study limits the light shed onto toxicity events and recurrences/survival that occur in the long term. To this extent, obtaining longer-term results from this and other cohorts is essential. An important potential limitation of single-shot IORT is the ability to sufficiently cover adequate target volumes with adequate doses.

In summary, this investigation provides preliminary corroborative data for the use of IORT in the boost setting. Along with a substantially low rate of postoperative complications, there were altogether few higher-grade toxicities along with appropriate outcomes for early breast cancer. These results should be corroborated by the eventual publication of randomized studies such as TARGIT-B.

Author Contribution T. Sprave, N. H. Nicolay: study conception and study design; R. Stoian, T. Erbes, C. Zamboglou, J. Scholber, E. Haehl, S. K. B. Spohn, A. Rühle, T. Sprave: data acquisition, data analysis, and data interpretation; T. Erbes, C. Zamboglou, M. Gainey and J. Scholber performed IORT; T. Sprave: statistical analysis, R. Stoian, T. Sprave, V. Verma, D. Krug: manuscript editing; R. Stoian, T. Erbes, V. Verma, D. Krug, C. Zamboglou, A. Rühle, I. Juhasz-Böss, A.L. Grosu, N. H. Nicolay, and T. Sprave: reviewed manuscript.

Funding Open Access funding enabled and organized by Projekt DEAL.

Conflict of interest R. Stoian, T. Erbes, C. Zamboglou, J. Scholber, M. Gainey, I. Sachpazidis, E. Haehl, S. K. B. Spohn, V. Verma, A. Rühle, I. Juhasz-Böss, A.-L. Grosu, N. H. Nicolay, and T. Sprave declare that they have no competing interests. D. Krug has received honoraria from Merck Sharp \& Dome outside the submitted work.

Open Access This article is licensed under a Creative Commons Attribution 4.0 International License, which permits use, sharing, adaptation, distribution and reproduction in any medium or format, as long as you give appropriate credit to the original author(s) and the source, provide a link to the Creative Commons licence, and indicate if changes were made. The images or other third party material in this article are included in the article's Creative Commons licence, unless indicated otherwise in a credit line to the material. If material is not included in the article's Creative Commons licence and your intended use is not permitted by statutory regulation or exceeds the permitted use, you will need to obtain permission directly from the copyright holder. To view a copy of this licence, visit http://creativecommons.org/licenses/by/4. $0 /$.

\section{References}

1. Early Breast Cancer Trialists' Collaborative G, Darby S, McGale P, Correa C, Taylor C, Arriagada R et al (2011) Effect of radiotherapy after breast-conserving surgery on 10-year recurrence and 15-year breast cancer death: meta-analysis of individual patient data for 10,801 women in 17 randomised trials. Lancet 378(9804):1707-1716

2. Bartelink H, Maingon P, Poortmans P, Weltens C, Fourquet A, Jager J et al (2015) Whole-breast irradiation with or without a boost for patients treated with breast-conserving surgery for early breast cancer: 20-year follow-up of a randomised phase 3 trial. Lancet Oncol 16(1):47-56
3. Harris EER, Small W Jr (2017) Intraoperative radiotherapy for breast cancer. Front Oncol 7:317

4. Pilar A, Gupta M, Ghosh Laskar S, Laskar S (2017) Intraoperative radiotherapy: review of techniques and results. ecancer 11:750

5. Vaidya JS, Wenz F, Bulsara M, Tobias JS, Joseph DJ, Keshtgar M et al (2014) Risk-adapted targeted intraoperative radiotherapy versus whole-breast radiotherapy for breast cancer: 5-year results for local control and overall survival from the TARGIT-A randomised trial. Lancet 383(9917):603-613

6. Veronesi U, Orecchia R, Maisonneuve P, Viale G, Rotmensz N, Sangalli C et al (2013) Intraoperative radiotherapy versus external radiotherapy for early breast cancer (ELIOT): a randomised controlled equivalence trial. Lancet Oncol 14(13):1269-1277

7. Fastner G, Reitsamer R, Urbanski B, Kopp P, Murawa D, Adamczyk B et al (2020) Toxicity and cosmetic outcome after hypofractionated whole breast irradiation and boost-IOERT in early stage breast cancer (HIOB): First results of a prospective multicenter trial (NCT01343459). Radiother Oncol 146:136-142

8. Valente SA, Tendulkar RD, Cherian S, Shah C, Ross DL, Lottich SC, Laronga C, Broman KK, Donnelly ED, Bethke KP, Shaw C, Lockney NA, Pederson A, Rudolph R, Hasselle M, Kelemen P, Hermanto U, Ashikari A, Kang S, Hoefer RA, McCready D, Fyles A, Escallon J, Rohatgi N, Graves J, Graves G, Willey SC, Tousimis E, Riley L, Deb N, Tu C, Small W Jr, Grobmyer SR (2021) TARGIT-R (retrospective): 5-year follow-up evaluation of intraoperative radiation therapy (IORT) for breast cancer performed in North America. Ann Surg Oncol 28(5):2512-2521. https://doi. org/10.1245/s10434-020-09432-3. PMID: 33433786

9. Coombs NJ, Coombs JM, Vaidya UJ, Singer J, Bulsara M, Tobias JS et al (2016) Environmental and social benefits of the targeted intraoperative radiotherapy for breast cancer: data from UK TARGIT-A trial centres and two UK NHS hospitals offering TARGIT IORT. BMJ Open 6(5):e10703

10. Strnad V, Hannoun-Levi JM, Guinot JL, Lossl K, Kauer-Dorner D, Resch A, Recommendations from GEC ESTRO Breast Cancer Working Group (I) (2015) Target definition and target delineation for accelerated or boost Partial Breast Irradiation using multicatheter interstitial brachytherapy after breast conserving closed cavity surgery. Radiother Oncol 115(3):342-348

11. Wenz F, Welzel G, Blank E, Hermann B, Steil V, Sutterlin M et al (2010) Intraoperative radiotherapy as a boost during breast-conserving surgery using low-kilovoltage X-rays: the first 5 years of experience with a novel approach. Int J Radiat Oncol Biol Phys 77(5):1309-1314

12. Pez M, Keller A, Welzel G, Abo-Madyan Y, Ehmann M, Tuschy B et al (2020) Long-term outcome after intraoperative radiotherapy as a boost in breast cancer. Strahlenther Onkol 196(4):349-355

13. Wenz F, Welzel G, Keller A, Blank E, Vorodi F, Herskind C et al (2008) Early initiation of external beam radiotherapy (EBRT) may increase the risk of long-term toxicity in patients undergoing intraoperative radiotherapy (IORT) as a boost for breast cancer. Breast 17(6):617-622

14. Kaiser J, Reitsamer R, Kopp P, Gaisberger C, Kopp M, Fischer T et al (2018) Intraoperative electron radiotherapy (IOERT) in the treatment of primary breast cancer. Breast Care 13(3):162-167

15. Fastner G, Hauser-Kronberger C, Moder A, Reitsamer R, Zehentmayr F, Kopp P et al (2016) Survival and local control rates of triple-negative breast cancer patients treated with boost-IOERT during breast-conserving surgery. Strahlenther Onkol 192(1):1-7

16. Fastner G, Reitsamer R, Ziegler I, Zehentmayr F, Fussl C, Kopp P et al (2015) IOERT as anticipated tumor bed boost during breastconserving surgery after neoadjuvant chemotherapy in locally advanced breast cancer-results of a case series after 5-year followup. Int J Cancer 136(5):1193-1201

17. Belletti B, Vaidya JS, D'Andrea S, Entschladen F, Roncadin M, Lovat $\mathrm{F}$ et al (2008) Targeted intraoperative radiotherapy impairs the 
stimulation of breast cancer cell proliferation and invasion caused by surgical wounding. Clin Cancer Res 14(5):1325-1332

18. Fabris L, Berton S, Citron F, D'Andrea S, Segatto I, Nicoloso MS et al (2016) Radiotherapy-induced miR-223 prevents relapse of breast cancer by targeting the EGF pathway. Oncogene 35(37):4914-4926

19. Clough KB, Kaufman GJ, Nos C, Buccimazza I, Sarfati IM (2010) Improving breast cancer surgery: a classification and quadrant per quadrant atlas for oncoplastic surgery. Ann Surg Oncol 17(5):1375-1391

20. Yang Z, Chen J, Hu W, Pan Z, Cai G, Yu X et al (2010) Planning the breast boost: how accurately do surgical clips represent the CT seroma? Radiother Oncol 97(3):530-534

21. Goldberg H, Prosnitz RG, Olson JA, Marks LB (2005) Definition of postlumpectomy tumor bed for radiotherapy boost field planning: CT versus surgical clips. Int J Radiat Oncol Biol Phys 63(1):209-213

22. Steel GG, Deacon JM, Duchesne GM, Horwich A, Kelland LR, Peacock JH (1987) The dose-rate effect in human tumour cells. Radiother Oncol 9(4):299-310

23. Whelan TJ, Kim DH, Sussman J (2008) Clinical experience using hypofractionated radiation schedules in breast cancer. Semin Radiat Oncol 18(4):257-264

24. Williams MV, Denekamp J, Fowler JF (1985) A review of alpha/ beta ratios for experimental tumors: implications for clinical studies of altered fractionation. Int J Radiat Oncol Biol Phys 11(1):87-96

25. Group ST, Bentzen SM, Agrawal RK, Aird EG, Barrett JM, Barrett-Lee PJ et al (2008) The UK Standardisation of Breast Radiotherapy (START) Trial B of radiotherapy hypofractionation for treatment of early breast cancer: a randomised trial. Lancet 371(9618):1098-1107

26. Group ST, Bentzen SM, Agrawal RK, Aird EG, Barrett JM, BarrettLee PJ et al (2008) The UK Standardisation of Breast Radiotherapy (START) Trial A of radiotherapy hypofractionation for treatment of early breast cancer: a randomised trial. Lancet Oncol 9(4):331-341

27. Haviland JS, Owen JR, Dewar JA, Agrawal RK, Barrett J, BarrettLee PJ et al (2013) The UK Standardisation of Breast Radiotherapy (START) trials of radiotherapy hypofractionation for treatment of early breast cancer: 10-year follow-up results of two randomised controlled trials. Lancet Oncol 14(11):1086-1094

28. Owen JR, Ashton A, Bliss JM, Homewood J, Harper C, Hanson J et al (2006) Effect of radiotherapy fraction size on tumour control in patients with early-stage breast cancer after local tumour excision: long-term results of a randomised trial. Lancet Oncol 7(6):467-471

29. Whelan T, MacKenzie R, Julian J, Levine M, Shelley W, Grimard L et al (2002) Randomized trial of breast irradiation schedules after lumpectomy for women with lymph node-negative breast cancer. J Natl Cancer Inst 94(15):1143-1150

30. Hopwood P, Haviland JS, Sumo G, Mills J, Bliss JM, Yarnold JR et al (2010) Comparison of patient-reported breast, arm, and shoulder symptoms and body image after radiotherapy for early breast cancer: 5-year follow-up in the randomised Standardisation of Breast Radiotherapy (START) trials. Lancet Oncol 11(3):231-240

31. Brunt AM, Haviland JS, Sydenham M, Agrawal RK, Algurafi H, Alhasso A et al (2020) Ten-year results of FAST: a randomized controlled trial of 5-fraction whole-breast radiotherapy for early breast cancer. J Clin Oncol 38(28):3261-3272

32. Gupta A, Khan AJ, Yegya-Raman N, Sayan M, Ahlawat S, Ohri N et al (2019) 5-year results of a prospective phase 2 trial evaluating 3-week hypofractionated whole breast radiation therapy inclusive of a sequential boost. Int J Radiat Oncol Biol Phys 105(2):267-274

33. Choi KH, Ahn SJ, Jeong JU, Yu M, Kim JH, Jeong BK et al (2020) Postoperative radiotherapy with intensity-modulated radiation therapy versus 3-dimensional conformal radiotherapy in early breast cancer: a randomized clinical trial of KROG 15-03. Radiother Oncol 154:179-186

34. Krug D, Koder C, Hafner MF, Arians N, Harrabi SB, Koerber SA et al (2020) Acute toxicity of normofractionated intensity modulated radiotherapy with simultaneous integrated boost compared to threedimensional conformal radiotherapy with sequential boost in the adjuvant treatment of breast cancer. Radiat Oncol 15(1):235

35. Joseph K, Vos LJ, Gabos Z, Pervez N, Chafe S, Tankel K, Warkentin H, Ghosh S, Amanie J, Powell K, Polkosnik LA, Horsman S, MacKenzie M, Sabri S, Parliament MB, Mackey J, Abdulkarim B (2021) Skin toxicity in early breast cancer patients treated with field-in-field breast intensity-modulated radiotherapy versus helical inverse breast intensity-modulated radiotherapy: results of a phase III Randomised controlled trial. Clin Oncol (R Coll Radiol) 33(1):30-39. https://doi.org/10.1016/j.clon.2020.07.005. PMID: 32711920

36. Blank E, Kraus-Tiefenbacher U, Welzel G, Keller A, Bohrer M, Sutterlin M et al (2010) Single-center long-term follow-up after intraoperative radiotherapy as a boost during breast-conserving surgery using low-kilovoltage x-rays. Ann Surg Oncol 17(Suppl 3):352-358

37. Chang DW, te Marvelde L, Chua BH (2014) Prospective study of local control and late radiation toxicity after intraoperative radiation therapy boost for early breast cancer. Int J Radiat Oncol Biol Phys 88(1):73-79

38. Fastner G, Sedlmayer F, Merz F, Deutschmann H, Reitsamer R, Menzel C et al (2013) IORT with electrons as boost strategy during breast conserving therapy in limited stage breast cancer: long term results of an ISIORT pooled analysis. Radiother Oncol 108(2):279-286

39. Ivaldi GB, Leonardi MC, Orecchia R, Zerini D, Morra A, Galimberti V et al (2008) Preliminary results of electron intraoperative therapy boost and hypofractionated external beam radiotherapy after breast-conserving surgery in premenopausal women. Int J Radiat Oncol Biol Phys 72(2):485-493

40. Lemanski C, Azria D, Thezenas S, Gutowski M, Saint-Aubert B, Rouanet $\mathrm{P}$ et al (2006) Intraoperative radiotherapy given as a boost for early breast cancer: long-term clinical and cosmetic results. Int J Radiat Oncol Biol Phys 64(5):1410-1415

41. Sedlmayer F, Reitsamer R, Fussl C, Ziegler I, Zehentmayr F, Deutschmann H et al (2014) Boost IORT in breast cancer: body of evidence. Int J Breast Cancer 2014:472516

42. Vaidya JS, Baum M, Tobias JS, Wenz F, Massarut S, Keshtgar M et al (2011) Long-term results of targeted intraoperative radiotherapy (Targit) boost during breast-conserving surgery. Int J Radiat Oncol Biol Phys 81(4):1091-1097

43. Wong WW, Pockaj BA, Vora SA, Halyard MY, Gray RJ, Schild SE (2014) Six-year outcome of a prospective study evaluating tumor bed boost with intra-operative electron irradiation followed by whole-breast irradiation for early-stage breast cancer. Breast $\mathrm{J}$ 20(2):125-130 